\title{
Can Arterial Spin-Labeling with Multiple Postlabeling Delays Predict Cerebrovascular Reserve?
}

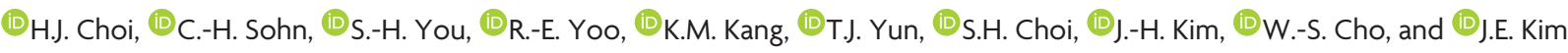

\begin{abstract}
BACKGROUND AND PURPOSE: The effect of delayed transit time is the main source of error in the quantitative measurement of CBF in arterial spin-labeling. In the present study, we evaluated the usefulness of the transit time-corrected CBF and arterial transit time delay from multiple postlabeling delays arterial spin-labeling compared with basal/acetazolamide stress technetium Tc99m-hexamethylpropylene amineoxime (Tc99m-HMPAO) SPECT in predicting impairment in the cerebrovascular reserve.
\end{abstract}

MATERIALS AND METHODS: Transit time-corrected CBF maps and arterial transit time maps were acquired in 30 consecutive patients with unilateral ICA or MCA steno-occlusive disease (severe stenosis or occlusion). Internal carotid artery territory-based ROIs were applied to both perfusion maps. Additionally, impairment in the cerebrovascular reserve was evaluated according to both qualitative and quantitative analyses of the ROIs on basal/acetazolamide stress Tc99m-HMPAO SPECT using a previously described method. The area under the receiver operating characteristic curve was used to evaluate the diagnostic accuracy of arterial spin-labeling in depicting impairment of the cerebrovascular reserve. The correlation between arterial spin-labeling and cerebrovascular reserve was evaluated.

RESULTS: The affected hemisphere had a decreased transit time-corrected CBF and increased arterial transit time compared with the corresponding values of the contralateral normal hemisphere, which were statistically significant $(P<.001)$. The percentage change of transit time-corrected CBF and the percentage change of arterial transit time were independently differentiating variables $(P<.001)$ for predicting cerebrovascular reserve impairment. The correlation coefficient between the arterial transit time and cerebrovascular reserve index ratio was -0.511 .

CONCLUSIONS: Our results demonstrate that the transit time-corrected CBF and arterial transit time based on arterial spin-labeling perfusion MR imaging can predict cerebrovascular reserve impairment.

ABBREVIATIONS: ASL = arterial spin-labeling; ATT = arterial transit time; CVR = cerebrovascular reserve; MP-ASL = multiphase ASL (Hadamard-encoded pseudocontinuous ASL with multiple postlabeling delays); $P L D=$ postlabeling delay; $r C V R=$ cerebrovascular reserve ratio; $R O C=$ receiver operating characteristic; $\mathrm{TCF}=$ transit time-corrected CBF; technetium Tc99m hexamethylpropylene amineoxime $=$ Tc99m HMPAO

A ssessment of hemodynamic abnormalities is important for managing cerebral ischemia and patients with Moyamoya disease, and the cerebrovascular reserve (CVR) has been consid-

Received May 25, 2017; accepted after revision September 4.

From the Department of Radiology (H.J.C.), CHA Bundang Medical Center, CHA University, Seongnam, Korea; Departments of Radiology (C.-H.S., R.-E.Y., K.M.K., T.J.Y., S.H.C., J.-H.K.) and Neurosurgery (W.-S.C., J.E.K.), Seoul National University Hospital, Seoul, Korea; and Department of Radiology (S.-H.Y.), Korea University Hospital, Seoul, Korea.

This study was supported by a grant from the Korean Health Technology R\&D Project, Ministry for Health, Welfare and Family Affairs, South Korea (A070001).

Paper previously presented at: Annual Meeting of the American Society of Neuroradiology, April 22-27, 2017; Long Beach, California.

Please address correspondence to Chul-Ho Sohn, MD, Department of Radiology, Seoul National University Hospital, 101, Daehangno, Jongno-gu, Seoul 110-744, Korea; e-mail: neurorad63@gmail.com

-- Indicates open access to non-subscribers at www.ajnr.org

http://dx.doi.org/10.3174/ajnr.A5439 ered the most useful predictor of cerebral hemodynamics. ${ }^{1}$ Several brain perfusion imaging techniques have been used to evaluate the CVR, including PET, SPECT, CTP, and DSC perfusion MR imaging. ${ }^{2,3}$ However, all these techniques require bolus injections of a contrast medium or radioactive tracers.

Basal/acetazolamide stress perfusion SPECT using an intravenous radiotracer, commonly technetium Tc99m-hexamethylpropylene amineoxime (Tc99m-HMPAO), is widely used because it can measure highly sensitive CVR in cerebral hemodynamics. ${ }^{4}$ Generally, acetazolamide is safe to administer and is well-tolerated $^{5}$; however, in one study, adverse reactions were reported in almost all healthy subjects (32 of 33 healthy subjects) following acetazolamide injection, such as headache or flushing. ${ }^{6}$ Moreover, severe or life-threatening adverse events have been reported, including reversible pontine ischemia, pulmonary edema, StevensJohnson syndrome, and anaphylaxis with the risk of morbidity 
and mortality. ${ }^{7-11}$ Several contraindications to acetazolamide also exist, including hypersensitivity to other sulfonamides or severe hepatic and renal disease. ${ }^{5}$

Arterial spin-labeling (ASL) perfusion MR imaging provides a noninvasive, repeatable method for quantifying the CBF using magnetically labeled arterial blood as an endogenous tracer without exposure to radiation and also provides higher spatial resolution than SPECT. ${ }^{12-14}$ However, ASL has certain drawbacks. The main problem is a time delay between the inversion of blood spins passing through the labeling plane in the neck and the images in any plane in the head after labeled blood flows into brain tissue. ${ }^{12,15}$ Cerebral steno-occlusive diseases, however, are generally accompanied by an elongation of the transit time because of the formation of collateral blood flow, which limits the validity of CBF determined by ASL. ${ }^{16-18}$ Thus, the postlabeling delay (PLD) is the most important parameter, and clinical studies have been performed with multiple PLDs with arterial transit time (ATT) correction to improve the quantification of CBF. ${ }^{16,18,19}$ With continuous ASL, direct measurement of the ATT could help improve perfusion quantification, particularly for vascular diseases with multiple different labeling times. However, these measurements can be very time-consuming and tend to have a low SNR. ${ }^{15,19-22}$ Hadamard-encoded pseudocontinuous ASL with multiple PLDs (multiphase ASL [MP-ASL]) was recently proposed as an approach to increase the SNR and time efficiency of multiple-labeling time acquisitions. ${ }^{22}$

In this study, we present MP-ASL perfusion in unilateral steno-occlusive disease to predict the CVR relative to the widely used Tc99m-HMPAO basal/acetazolamide stress perfusion SPECT.

\section{MATERIALS AND METHODS \\ Patients}

This retrospective study was approved by the Seoul National University Hospital institutional review board. Between June 2015 and December 2016, ninety-eight consecutive patients with unilateral ICA or MCA steno-occlusive disease (severe stenosis [>70\%] or occlusion) who had undergone ASL perfusion MR imaging and SPECT were included in this study. The exclusion criteria were as follows: 1) patients with contralateral moderate or severe stenosis, 2) a time interval between ASL perfusion MR imaging and SPECT of $>1$ month, and 3) poor image quality because of a previous hemorrhage or operation. Thirty patients were ultimately enrolled in this study. Eleven patients had undergone superficial temporal artery-middle cerebral artery anastomosis, and 1 patient had undergone proximal ICA stent placement. Four patients who had anastomosis surgery had preoperative and postoperative examination sets (preoperative ASL and SPECT and postoperative ASL and SPECT), and their images were analyzed separately. Consequently, 34 ASL and SPECT images from 30 patients were analyzed in this study. Two patients were diagnosed with unilateral Moyamoya disease, and 28 patients were diagnosed with non-Moyamoya steno-occlusive disease. All patients had severe stenosis or total occlusion of the unilateral ICAs or MCAs, as determined by MRA or DSA. There were 12 female and 18 male patients (a total of 30 patients with a mean age of 55.5 years and an age range of $16-82$ years [male patients had a mean age of 59.2 years and age range of $48-82$ years, and female patients had a mean age of 49.2 years and age range of $16-72$ years]), with no significant difference in the age between male and female patients $(P=.12)$. Patients had either distal ICA occlusion $(n=5)$, proximal ICA occlusion $(n=12)$, proximal ICA severe stenosis $(n=2)$, proximal MCA occlusion $(n=8)$, or proximal MCA/ anterior cerebral artery occlusion $(n=3)$.

\section{MR Imaging Protocol and Postprocessing}

MR images were obtained with a 3T MR imaging scanner (Discovery MR750w; GE Healthcare, Milwaukee, Wisconsin) with a 32-channel head coil. We used the following 3D ASL protocol: TR, 5868.0 ms; TE, $11.0 \mathrm{~ms}$; section thickness, $6 \mathrm{~mm}$; NEX, 1; readout, 4 arms $\times 640$ samples; 26 sections; FOV, $24 \times 24 \mathrm{~cm}^{2}$; and reconstructed in a plane voxel resolution, $1.88 \times 1.88 \mathrm{~mm}^{2}$. The total examination time for the ASL protocol was 3 minutes 57 seconds. All patients who underwent perfusion studies could tolerate MR imaging. This protocol encodes 7 different PLD times into a single acquisition. With the parameters tabulated above, images with PLD times of 1.00, 1.22, 1.48, 1.78, 2.15, 2.63, and 3.32 seconds and effective label durations of $0.22,0.26,0.30,0.37$, $0.48,0.68$, and 1.18 seconds were reconstructed. These PLD times were intended to probe the bolus arrival time. The ATT map $(\delta)$ and perfusion map $(f)$ were calculated by fitting the 7-delays ASL difference signals as a function of the PLD $(w)$ to the following equation:

$$
\begin{aligned}
\Delta M=2 M_{\mathrm{t}}^{0} \times \beta \times & \alpha \times T 1 t \times f \times e^{-\delta / T 1 a} \\
& \times\left[e^{-\max (w-\delta, 0) / T 1 t}-e^{-\max (\tau+w-\delta, 0) / T 1 t}\right] / \lambda,{ }^{23}
\end{aligned}
$$

where $\Delta M$ is the ASL difference signal, $f$ is the perfusion rate, T1 $a$ and $\mathrm{T} 1 t$ are the longitudinal relaxation times of blood and tissue, $M_{\mathrm{t}}^{0}$ is the fully relaxed equilibrium magnetization of brain tissue, $\alpha$ is the efficiency of the labeling sequence, $\lambda$ is the tissue-to-blood partition coefficient of water, $\delta$ is the transit delay, $\tau$ is the labeling duration, and $w$ is the PLD. Vascular signal suppression is assumed in this model. $\beta$ has been added to the kinetic model to compensate for any static tissue signal loss caused by the vesselsuppression pulses. Notice that for $\delta$ less than $w, \delta$ completely disappears from the equation. ${ }^{22-26}$

\section{SPECT Imaging Protocol}

Basal/acetazolamide brain perfusion SPECT was performed with a 1-day protocol. Basal SPECT images were acquired 5 minutes after intravenous injection of Tc99m-HMPAO (9.25 MBq per kilogram of body weight) using a triple-headed gamma camera (Triad XLT 9; Trionix Research Laboratory, Twinsburg, Ohio) equipped with low-energy ultra-high-resolution fan-beam collimators. Image acquisition was performed with a step-and-shoot mode with 40 steps for 20 seconds per step (total duration, 13.3 minutes). Ten minutes before the end of the basal SPECT, 14 $\mathrm{mg} / \mathrm{kg}$ of acetazolamide was intravenously injected. Another dose of Tc99m-HMPAO (18.5 MBq per kilogram of body weight) was injected at the end of basal SPECT, and a second acquisition of SPECT was started 5 minutes later. The acetazolamide stress perfusion images were generated by using decay-corrected subtraction of the basal images from the corresponding stress images. All SPECT images were reconstructed on $128 \times 128$ matrices by using a filtered back-projection method with a Butterworth filter. 


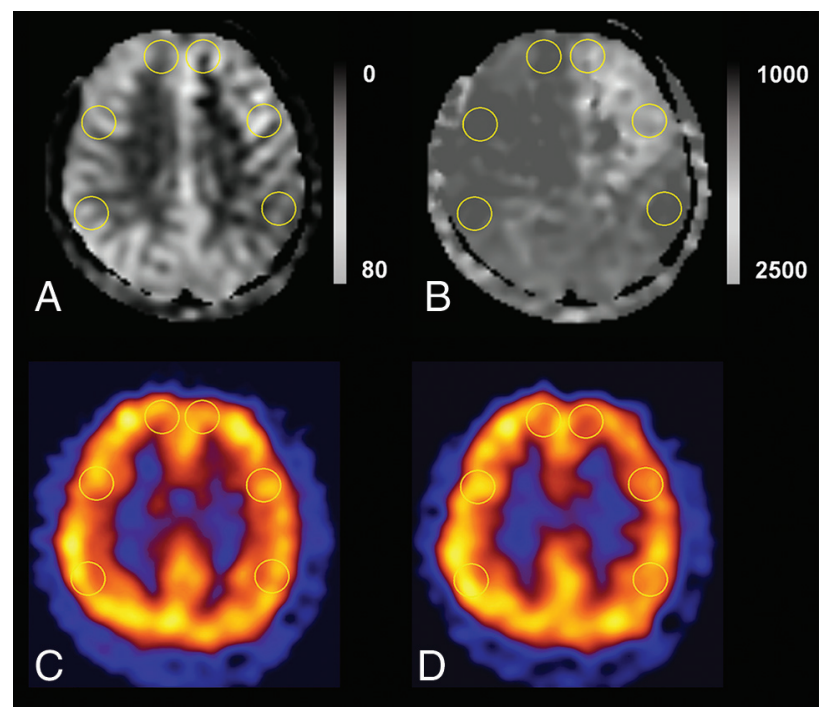

FIG 1. ROI placements in supraventricular levels on ASL and SPECT. We drew the ROIs in the bilateral anterior cerebral artery territories and anterior and posterior MCA territories in $\operatorname{TCF}(A), \operatorname{ATT}(B)$, baseline SPECT (C), and acetazolamide challenge SPECT (D). We also drew an $\mathrm{ROI}$ in the ipsilateral cerebellum with the highest uptake on visual assessment for normalization of SPECT values.

\section{ASL MR Imaging and SPECT Imaging Analysis}

All MR imaging and basal/acetazolamide SPECT scans were reviewed by board-certified reviewer 1 (H.J.C. with 6 years of experience in radiology). Unclear interpretations were subsequently resolved in consensus with board-certified reviewer 2 (C.H.S. with $>20$ years of experience in radiology). The same analysis was performed by board-certified reviewer 3 (S.H.Y. with 6 years of experience in radiology).

\section{Quantitative Assessment of ASL-Derived ATT and Transit Time-Corrected CBF}

On ASL MR imaging, ROIs were drawn in the gray matter of the major territories of the intracranial arteries and the equivalent site on the contralateral normal side on the ATT and transit time-corrected CBF (TCF) maps directly in the workstation (Fig 1). The ROIs were placed in 6 locations (2 bilateral anterior cerebral artery territories and 4 bilateral MCA territories) on the supraventricular level over a fixed territory in all patients to avoid the infarcted area. ATT $[\mathrm{ms}]$ and TCF $[\mathrm{mL} / 100 \mathrm{~g} / \mathrm{min}]$ were obtained in each territory. The percentage change of TCF is calculated as $100 \times\left[\left(\mathrm{TCF}_{\text {contralateral normal }}-\mathrm{TCF}_{\text {ipsilateral affected }}\right) /\right.$ $\mathrm{TCF}_{\text {contralateral normal }}$, and the percentage change of ATT is calculated as $100 \times\left[\left(\mathrm{ATT}_{\text {contralateral normal }}-\mathrm{ATT}_{\text {ipsilateral affected }}\right) /\right.$ $\mathrm{ATT}_{\text {contralateral normal }}$.

\section{Qualitative and Quantitative Assessment of SPECT-Derived CVR and Cerebrovascular Reserve Index}

The SPECT data were assessed qualitatively and quantitatively. Regions of known old infarction with perfusion defects were not included for visual grading. The visual grades of reduced CVR were classified into 1 of 2 grades, preserved or impaired. Impairment of the CVR was defined as no increase or decrease in perfusion in acetazolamide stress SPECT compared with basal SPECT. Visual grading was performed on each side of the hemispheres relative to the normal contralateral side.
Table 1: ASL parameter values of each $\mathrm{ROI}^{\mathrm{a}}$

\begin{tabular}{|c|c|c|c|}
\hline \multirow[b]{2}{*}{ ASL Parameters } & \multicolumn{3}{|c|}{ Absolute Values } \\
\hline & $\begin{array}{c}\text { Contralateral } \\
\text { Unaffected ROIs }\end{array}$ & $\begin{array}{c}\text { Ipsilateral } \\
\text { Affected ROls }\end{array}$ & $P$ \\
\hline $\mathrm{TCF}(\mathrm{mL} / 100 \mathrm{~g} / \mathrm{min})$ & $46.00 \pm 8.89$ & $34.81 \pm 14.58$ & $<.001$ \\
\hline ATT (ms) & $1235.49 \pm 142.40$ & $1643.71 \pm 240.03$ & $<.001$ \\
\hline
\end{tabular}

${ }^{a}$ Values are means.

For quantitative analysis, reviewers created 7 ROIs in the major arterial territories with an equivalent location on ASL images (2 bilateral anterior cerebral artery territories, 4 bilateral MCA territories, and 1 ipsilateral cerebellum for normalization), which were the same locations examined in the ASL images. The cerebrovascular reserve index $\left(\mathrm{CVR}_{\text {index }}\right)$ in each arterial territory was defined as $100 \times\left[\left(\mathrm{CBF}_{\text {Acetazolamide }}-\mathrm{CBF}_{\text {Baseline }}\right) / \mathrm{CBF}_{\text {Baseline }}\right]$, where $\mathrm{CBF}_{\text {Acetazolamide }}$ and $\mathrm{CBF}_{\text {Baseline }}$ were normalized by the ipsilateral cerebellar $\mathrm{CBF}$, which was measured by drawing an ROI in the highest uptake on visual inspection. ${ }^{27}$ Furthermore, the cerebrovascular reserve index ratio $\left(\mathrm{rCVR}_{\text {index }}\right)$ was defined as $100 \times\left[\left(\mathrm{rCBF}_{\text {Acetazolamide }}-\mathrm{rCBF}_{\text {Baseline }}\right) / \mathrm{rCBF}_{\text {Baseline }}\right]$. The $\mathrm{rCBF}$ indicates the asymmetric ratio, which is normalized $\mathrm{CBF}$ value by the contralateral unaffected side. ${ }^{27}$

\section{Statistical Analysis}

To evaluate the ability of the ATT delay and TCF to predict impairment of the CVR, we performed a receiver operating characteristic (ROC) curve analysis to identify the optimal threshold for maximizing the sensitivity and specificity. In addition, pair-wise comparisons of the ROC curves were performed to compare the diagnostic accuracy of TCF, the percentage change of TCF ATT, and the percentage change of ATT. The correlation between ASL parameters and SPECT-derived $\mathrm{CVR}_{\text {index }}$ was determined by the Pearson correlation coefficient. Interobserver agreement for qualitative analysis of CVR in SPECT was evaluated by the weighted $\kappa$ coefficient. The quantitative analysis for the $\mathrm{CVR}_{\text {index }}$ on SPECT and the quantitative analysis for ATT and TCF on ASL were assessed with the intraclass correlation coefficient. Weighted $\kappa$ values or intraclass correlation coefficient of $<0.20,0.21-0.40$, $0.41-0.60,0.61-0.80$, and $0.81-1.00$ represented poor, fair, moderate, good, and excellent agreement, respectively. ${ }^{28}$ All statistical analyses were performed with SPSS statistics, Version 20.0 (IBM, Armonk, New York); R statistical and computing software (http://www.r-project.org/); and MedCalc Statistical Software, Version 17.1 (MedCalc Software, Mariakerke, Belgium). A P value $<.05$ was considered statistically significant.

\section{RESULTS}

\section{Time Interval between Examinations}

The mean interval between ASL and SPECT examinations was $1.7 \pm 4.9$ days (range, $0-28$ days).

\section{Comparison of ASL Parameters between the Affected and Contralateral Unaffected ROIs}

Table 1 shows the mean absolute values of ASL parameters of the affected and contralateral unaffected ROIs. The affected ROIs had a decreased TCF and increased ATT compared with the corresponding values of the contralateral normal unaffected ROIs, which were statistically significant $(P<.001)$. Because a higher correlation was 
Table 2: Diagnostic performance of the ASL parameters for predicting CVR impairment

\begin{tabular}{|c|c|c|c|c|c|c|}
\hline & Mean & $\begin{array}{l}\text { Area under } \\
\text { ROC Curve }\end{array}$ & $\begin{array}{l}\text { Associated } \\
\text { Criterion }\end{array}$ & Sensitivity & Specificity & $P$ \\
\hline TCF (mL/100 g/min) & $40.40 \pm 13.27^{a}$ & $0.822(0.747-0.882)^{\mathrm{b}}$ & $\leq 33.00$ & 62.00 & 93.02 & $<.001$ \\
\hline Percentage change of TCF (\%) & $12.55 \pm 21.86^{\mathrm{a}}$ & $0.905(0.843-0.949)^{b}$ & $>7.14$ & 84.00 & 97.67 & $<.001$ \\
\hline $\mathrm{ATT}(\mathrm{ms})$ & $1439.59 \pm 283.95^{\mathrm{a}}$ & $0.891(0.826-0.938)^{b}$ & $>1527$ & 82.00 & 88.37 & $<.001$ \\
\hline Percentage change of ATT (\%) & $-17.57 \pm 26.24^{a}$ & $0.889(0.823-0.936)^{b}$ & $\leq-8.86$ & 94.00 & 87.21 & $<.001$ \\
\hline
\end{tabular}

a Data are means.

${ }^{\mathrm{b}}$ Data in parentheses are $95 \%$ confidence intervals.

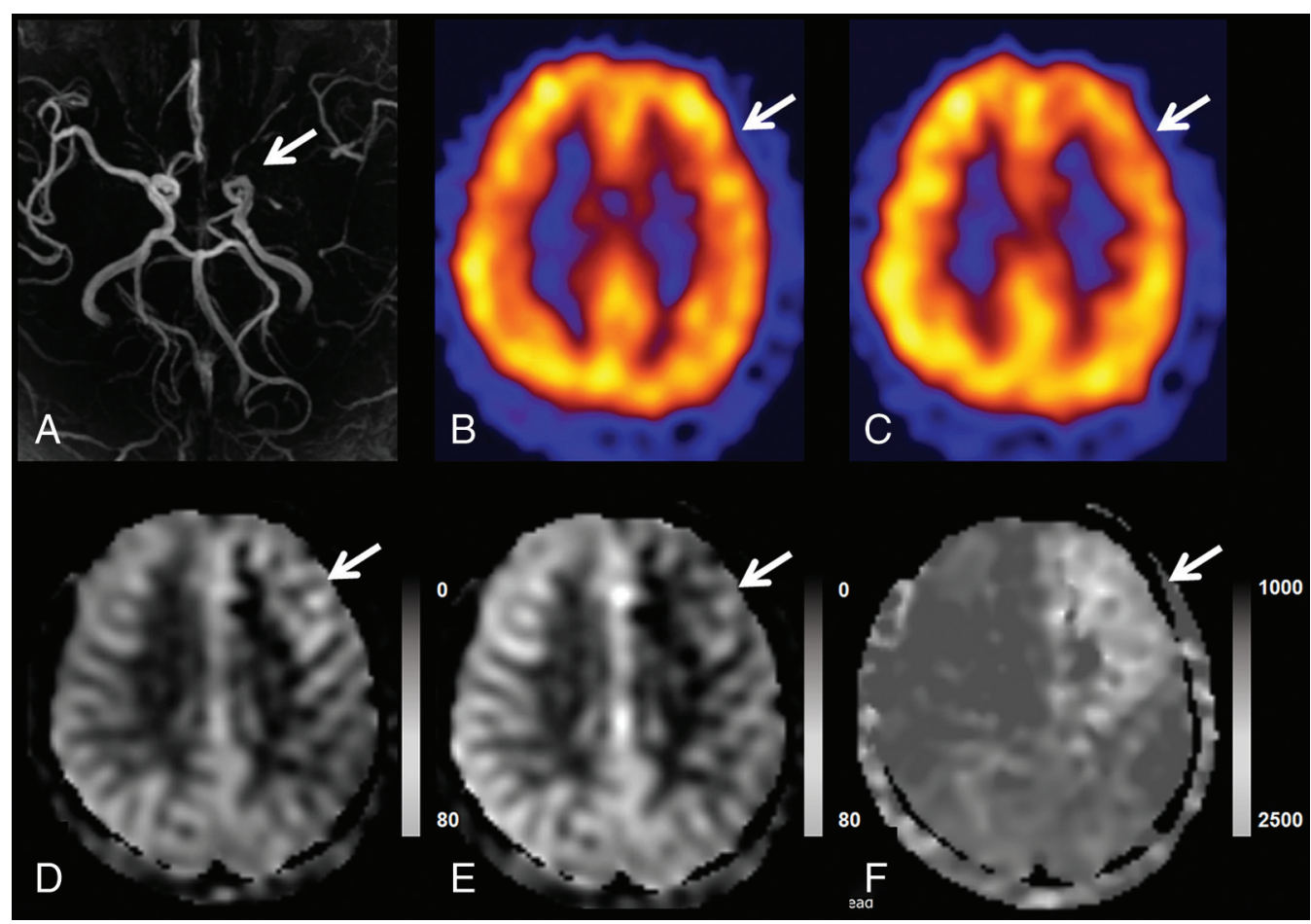

FIG 2. A representative case of the use of the TCF and ATT maps in depicting CVR impairment. TOF MRA (A) demonstrates left proximal MCA occlusion. Basal/acetazolamide Tc99m-HMPAO SPECT images ( $B$ and $C$ ) show normal perfusion on basal SPECT and decreased perfusion in the left frontal lobe (MCA M2, superior division territory) on acetazolamide challenge SPECT, which indicates impairment of the CVR in this region. In ASL without a time correction $(D)$, there is no hypoperfusion; however, TCF from MP-ASL $(E)$ demonstrates decreased perfusion and delayed ATT ( $F$ ).

noted in the MCA territory than in the anterior cerebral artery territory, we focused on the MCA territory in subsequent results.

\section{Diagnostic Performance of ASL Parameters in the Prediction of CVR Impairment}

In qualitative assessment of baseline and acetazolamide challenge SPECT, 20 patients $(66.67 \%)$ showed impairment of CVR on the affected side. Eight patients (26.67\%) showed preserved CVR even in ipsilateral steno-occlusive disease. In addition, we evaluated 136 ROIs: Fifty ROIs showed impaired CVR and 86 ROIs showed preserved CVR. Four patients who had bypass surgery showed impaired CVR on qualitative assessment in preoperative and postoperative SPECT. Results pertaining to the diagnostic performance of TCF and ATT in predicting CVR impairment based on a qualitative assessment of SPECT data are summarized in Table 2. The percentage change of TCF showed the best area under the curve value (0.905) in predicting CVR impairment. A significant difference was found in the pair-wise comparison of the areas under the ROC curve between TCF and the percentage change of transit time (difference between areas $=0.083, P=$ .015). Otherwise, there was no significant difference among the areas under the ROC curve. A representative case of TCF and ATT used in depicting the CVR impairment is shown in Fig 2.

\section{Correlation between ASL Parameters and SPECT-Derived Parameters}

The correlation between ASL parameters and SPECT-derived parameters is summarized in Fig 3. The TCF showed a positive correlation with the $\mathrm{CVR}_{\text {index }}$ or $\mathrm{rCVR}_{\text {index }}$, and the ATT showed a negative correlation with the $\mathrm{CVR}_{\text {index }}$ or $\operatorname{rCVR}_{\text {index }}(P<.001$, respectively).

\section{Interobserver Agreement for MP-ASL Parameters, Qualitative Assessment of CVR, and Quantitative Assessment of CVR Based on SPECT}

Interobserver agreement for the visual assessment of the impairment of CVR based on SPECT (weighted $\kappa=0.950$ ), measurement of the basal CBF in SPECT (intraclass correlation coefficient $=0.964$ ), acetazolamide challenge CBF in SPECT (intraclass correlation coefficient $=0.968$ ), TCF in ASL (intraclass correlation coefficient $=0.902$ ), and the ATT in ASL (intraclass correlation coefficient $=0.966$ ) was excellent. 

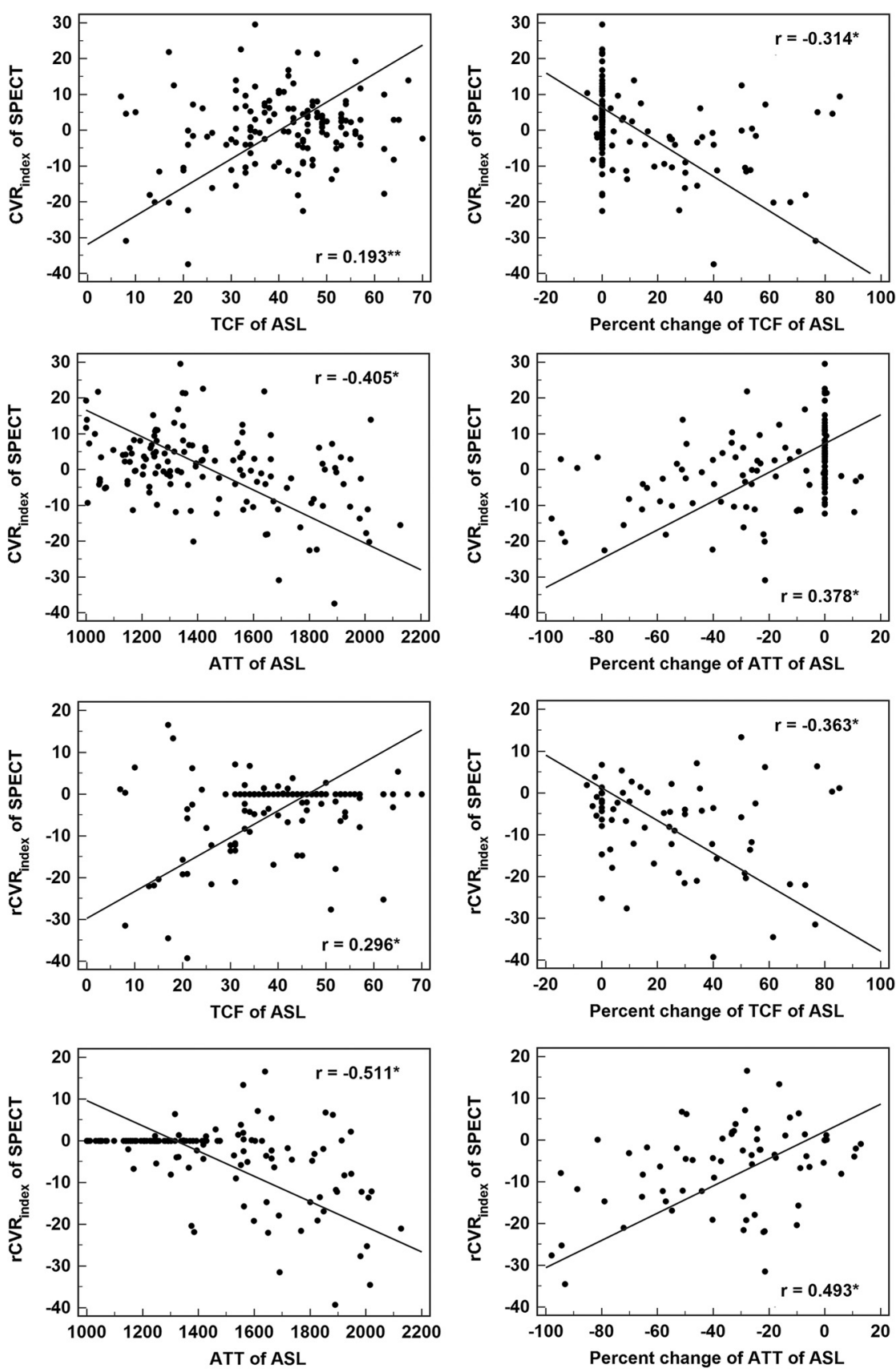

FIG 3. Scatterplots and Pearson correlation coefficients between values of ASL and SPECT of MCA territories (the asterisk indicates $P<.001$; double asterisks, $P=.007$ ).

\section{DISCUSSION}

The present study demonstrated that TCF and ATT measurements made by MP-ASL can predict CVR without acetazolamide in patients with unilateral steno-occlusive disease. Therefore, ASL can reduce the number of examinations for patients who require frequent follow-up to evaluate CVR without the acetazolamide challenge SPECT.

Many studies have examined the relationship between hemodynamic parameters and metabolic reserve. Based on a PET study, Gibbs et $\mathrm{al}^{29}$ suggested that the ratio CBF/CBV (reciprocal of the MTT) is an index of diminishing cerebral perfusion pressure, and even without a measurement of the regional oxygen extraction ratio, the MTT can provide the best predictive value for cerebro- vascular reserve. Schumann et $\mathrm{al}^{30}$ also demonstrated that the MTT was linearly correlated with cerebral perfusion pressure under physiologic conditions and may be sensitive to metabolic reserve consumption. Vagal et $\mathrm{al}^{5}$ reported that the MTT is 1 of 3 general approaches for assessing CVR in the same position as CBF measurements by the acetazolamide challenge and direct oxygen extraction fraction measurements. The MTT determination based on perfusion CT or DSC-MR imaging showed a strong correlation with CVR in patients with chronic vascular occlusive disease. ${ }^{31-33}$ The ATT is different from the MTT; however, it has been reported that there was significant correlation between the ATT and MTT $(r=0.604, P=$ $.01) .{ }^{16}$ To the best of our knowledge, there is no prior study about the correlation between the ATT and the CVR based on SPECT with acetazolamide challenge. With respect to predicting the CVR from baseline SPECT CBF scans, we found a poorer correlation between baseline CBF and $\mathrm{CVR}_{\text {index }}(r=-0.279$, $P=.021)$ than for ATT or TCF and no significant correlation between baseline CBF and $\mathrm{rCVR}_{\text {index }}(r=-0.058, P=$ .637). These results are like those of studies indicating that CBF has no correlation with CVR or a poorer correlation than the MTT. ${ }^{3,34}$ However, we observed a better correlation between the percentage change in the TCF and $\operatorname{rCVR}_{\text {index }}(r=-0.363, P<.001)$. The percentage change in the TCF showed excellent diagnostic performance in predicting CVR with a sensitivity of $84.00 \%$, specificity of $97.67 \%$, and an area under the ROC curve of 0.905 . In addition, the correlation between the ATT and $\mathrm{rCVR}_{\text {index }}$ was moderate $(r=$ $-0.511, P<.001)$. The ATT showed excellent diagnostic performance in predicting CVR with a sensitivity of $82.00 \%$, specificity of $88.37 \%$, and an area under the ROC curve of 0.891 . According to our results, the TCF and ATT have potential value in predicting CVR.

In a previous study, the CVR index by ASL with an acetazolamide challenge in monitoring Moyamoya disease showed excellent performance in the identification of impaired CVR, which was based on single postlabeling delay ASL and the use of acetazolamide. ${ }^{35}$ Comparable results have been reported for respiratory challenge MR imaging in hypercapnia or breathing control in the assessment of CVR with use of ASL and blood oxygen leveldependent techniques. ${ }^{36}$ Although these methods provide useful 
information about CVR in a safe, noninvasive, and repeatable manner at high temporal and spatial resolution, there may be restrictions on the use of the complex equipment associated with the procedure, such as gas concentration control, the use of a mask or ventilator, the use of visual cueing or a pneumatic belt for paced breathing, and patient-training before the MRI scan. ${ }^{36}$

Single PLD ASL imaging provides rapid and robust measurements of CBF. However, the method does not provide measurements of the ATT. ATT prolongation causes underestimation of $\mathrm{CBF}$, and such effects might be particularly important in patients with steno-occlusive diseases. In a recent recommendation for the clinical application of ASL from the International Society for Magnetic Resonance in Medicine consensus, the authors mentioned that the complex-but-efficient Hadamard time-encoding strategies of ASL can provide additional information of the estimation of ATT and the most precise quantitation of CBF, especially in steno-occlusive disease. ${ }^{12}$ The MP-ASL speeds imaging and efficiently improves the SNR. ${ }^{22}$ Additionally, we found the feasibility of MP-ASL in predicting CVR in patients with stenoocclusive disease who had a long transit time from labeling to scanning without the use of a vasodilatory stimulus (such as acetazolamide) or contrast (iodinate or gadolinium base). This protocol encoded 7 different PLD times with the application of 7 effective label durations. Because the ASL signal increases with label duration, Alsop et al ${ }^{12}$ suggested a labeling duration of 1.8 seconds as a compromise between an increase in the SNR and the disadvantage of greater power deposition and $\mathrm{T} 1$ sensitivity in a single postlabeling delay ASL. We used 7 shorter effective label durations (range, 0.22-1.18 seconds) than the duration recommended by Alsop et al. A previous study demonstrated a trade-off between systematic error and the SNR using standard continuous ASL versus the Hadamard continuous arterial spin-labeling method. ${ }^{22}$ Because Hadamard encoding can remove transit timerelated systematic errors, it holds an advantage for clinical applications, particularly for patients with steno-occlusive disease, for whom the range of prolonged ATT values is variable or unknown.

Acetazolamide acts quickly: an increase of CBF up to $53 \% \pm$ $24 \%$ in 3 minutes after $1 \mathrm{~g}$ of acetazolamide administration. ${ }^{37}$ The SPECT protocol in this study was administration of acetazolamide 10 minutes before the end of baseline SPECT. One of the purposes of the protocol is to save time to avoid motion artifacts. Acetazolamide can be injected during the baseline scan to optimize the effect of the drug at the end of the test. The Tc99m-HMPAO that we use for imaging is characterized by being fixed in the brain within 2 minutes after injection. ${ }^{38}$ Even if other medications are introduced in the middle of the scan (and even if the blood flow is changed), the fixed status does not change.

This study has a few limitations. First, we did not divide the patient group into atherosclerotic stenosis and unilateral Moyamoya disease groups, which are different pathophysiologies of vascular stenosis, collateral formation, and consequent arterial transit delay. ${ }^{39}$ However, this protocol covered a long PLD (the longest postlabeling time was 3.32 seconds), which would not be affected by the long ATT. Second, we used SPECT as a reference standard for CVR impairment rather than PET, which has usually been considered a standard for CBF quantification. However, some studies have shown that SPECT can be an alternative method for CBF assessment in patients with cerebrovascular disease. ${ }^{40}$ Third, because the measurements of CVR and $\mathrm{CVR}_{\text {index }}$ were made via a 1-day protocol of Tc99m-HMPAO SPECT with a split dose, we should normalize the values by the ipsilateral cerebellum or contralateral equivalent normal side to obtain the adjusted quantification. Fourth, we did not control for conditions that could cause variations in $\mathrm{CBF}$, such as caffeine, time of day, or diet, and the examinations were not performed back to back. ${ }^{41}$ We used percent change of values and asymmetric ratio in addition to the absolute values to reduce uncontrolled variations.

\section{CONCLUSIONS}

MP-ASL can predict cerebrovascular reserve without acetazolamide in patients with unilateral steno-occlusive disease. ASL can provide a potential noninvasive imaging tool for measuring CVR impairment.

\section{REFERENCES}

1. Derdeyn CP, Grubb RL Jr, Powers WJ. Cerebral hemodynamic impairment: methods of measurement and association with stroke risk. Neurology 1999;53:251-59 CrossRef Medline

2. Wintermark M, Sesay M, Barbier E, et al. Comparative overview of brain perfusion imaging techniques. Stroke 2005;36:e83-99 CrossRef Medline

3. Kim E, Sohn CH, Na DG, et al. Perfusion computed tomography evaluation of cerebral hemodynamic impairment in patients with unilateral chronic steno-occlusive disease: a comparison with the acetazolamide challenge $99 \mathrm{mTc}$-hexamethylpropyleneamine oxime single-photon emission computed tomography. J Comput Assist Tomogr 2009;33:546-51 CrossRef Medline

4. Barber PA, Consolo HK, Yang Q, et al. Comparison of MRI perfusion imaging and single photon emission computed tomography in chronic stroke. Cerebrovasc Dis 2001;11:128-36 CrossRef Medline

5. Vagal AS, Leach JL, Fernandez-Ulloa M, et al. The acetazolamide challenge: techniques and applications in the evaluation of chronic cerebral ischemia. AJNR Am J Neuroradiol 2009;30:876-84 CrossRef Medline

6. Sullivan HG, Kingsbury TB 4th, Morgan ME, et al. The rCBF response to Diamox in normal subjects and cerebrovascular disease patients. J Neurosurg 1987;67:525-34 CrossRef Medline

7. Komiyama M, Nishikawa M, Yasui T, et al. Reversible pontine ischemia caused by acetazolamide challenge. AJNR Am J Neuroradiol 1997;18:1782-84 Medline

8. Zimmermann S, Achenbach S, Wolf M, et al. Recurrent shock and pulmonary edema due to acetazolamide medication after cataract surgery. Heart Lung 2014;43:124-26 CrossRef Medline

9. Her Y, Kil MS, Park JH, et al. Stevens-Johnson syndrome induced by acetazolamide. J Dermatol 2011;38:272-75 CrossRef Medline

10. Hu CY, Lee BJ, Cheng HF, et al. Acetazolamide-related life-threatening hypophosphatemia in a glaucoma patient. J Glaucoma 2015; 24:e31-33 CrossRef Medline

11. Kelly TE, Hackett PH. Acetazolamide and sulfonamide allergy: a not so simple story. High Alt Med Biol 2010;11:319-23 CrossRef Medline

12. Alsop DC, Detre JA, Golay X, et al. Recommended implementation of arterial spin-labeled perfusion MRI for clinical applications: a consensus of the ISMRM perfusion study group and the European consortium for ASL in dementia. Magn Reson Med 2015;73:102-16 CrossRef Medline

13. Deibler AR, Pollock JM, Kraft RA, et al. Arterial spin-labeling in routine clinical practice, Part 1: technique and artifacts. AJNR Am J Neuroradiol 2008;29:1228-34 CrossRef Medline

14. Alsop DC, Detre JA, Grossman M. Assessment of cerebral blood flow in Alzheimer's disease by spin-labeled magnetic resonance imaging. Ann Neurol 2000;47:93-100 Medline

15. Haga S, Morioka T, Shimogawa T, et al. Arterial spin labeling perfu- 
sion magnetic resonance image with dual postlabeling delay: a correlative study with acetazolamide loading (123)I-iodoamphetamine single-photon emission computed tomography. J Stroke Cerebrovasc Dis 2016;25:1-6 CrossRef Medline

16. Wang R, Yu S, Alger JR, et al. Multi-delay arterial spin labeling perfusion MRI in Moyamoya disease-comparison with CT perfusion imaging. Eur Radiol 2014;24:1135-44 CrossRef Medline

17. Yun TJ, Sohn $\mathrm{CH}$, Han $\mathrm{MH}$, et al. Effect of delayed transit time on arterial spin labeling: correlation with dynamic susceptibility contrast perfusion magnetic resonance in Moyamoya disease. Invest Radiol 2013;48:795-802 CrossRef Medline

18. MacIntosh BJ, Lindsay AC, Kylintireas I, et al. Multiple inflow pulsed arterial spin-labeling reveals delays in the arterial arrival time in minor stroke and transient ischemic attack. AJNR Am J Neuroradiol 2010;31:1892-94 CrossRef Medline

19. Wang DJ, Alger JR, Qiao JX, et al; UCLA Stroke Investigators. Multidelay multi-parametric arterial spin-labeled perfusion MRI in acute ischemic stroke: comparison with dynamic susceptibility contrast enhanced perfusion imaging. Neuroimage Clin 2013;3:1-7 CrossRef Medline

20. Bokkers RP, Bremmer JP, van Berckel BN, et al. Arterial spin labeling perfusion MRI at multiple delay times: a correlative study with $\mathrm{H}(2)(15) \mathrm{O}$ positron emission tomography in patients with symptomatic carotid artery occlusion. J Cereb Blood Flow Metab 2010;30: 222-29 CrossRef Medline

21. Chalela JA, Alsop DC, Gonzalez-Atavales JB, et al. Magnetic resonance perfusion imaging in acute ischemic stroke using continuous arterial spin labeling. Stroke 2000;31:680-87 CrossRef Medline

22. Dai W, Shankaranarayanan A, Alsop DC. Volumetric measurement of perfusion and arterial transit delay using Hadamard encoded continuous arterial spin labeling. Magn Reson Med 2013;69:1014-22 CrossRef Medline

23. Alsop DC, Detre JA. Reduced transit-time sensitivity in noninvasive magnetic resonance imaging of human cerebral blood flow. J Cereb Blood Flow Metab 1996;16:1236-49 CrossRef Medline

24. Dai W, Robson PM, Shankaranarayanan A, et al. Reduced resolution transit delay prescan for quantitative continuous arterial spin labeling perfusion imaging. Magn Reson Med 2012;67:1252-65 CrossRef Medline

25. Buxton RB, Frank LR, Wong EC, et al. A general kinetic model for quantitative perfusion imaging with arterial spin labeling. Magn Reson Med 1998;40:383-96 CrossRef Medline

26. Wang J, Alsop DC, Li L, et al. Comparison of quantitative perfusion imaging using arterial spin labeling at 1.5 and 4.0 Tesla. Magn Reson Med 2002;48:242-54 CrossRef Medline

27. Martí-Fàbregas JA, Catafau AM, Marí C, et al. Cerebral perfusion and haemodynamics measured by SPET in symptom-free patients with transient ischaemic attack: clinical implications. Eur J Nucl Med 2001;28:1828-35 CrossRef Medline

28. Landis JR, Koch GG. The measurement of observer agreement for categorical data. Biometrics 1977;33:159-74 CrossRef Medline

29. Gibbs JM, Wise RJ, Leenders KL, et al. Evaluation of cerebral perfu- sion reserve in patients with carotid-artery occlusion. Lancet 1984; 1:310-14 Medline

30. Schumann P, Touzani O, Young AR, et al. Evaluation of the ratio of cerebral blood flow to cerebral blood volume as an index of local cerebral perfusion pressure. Brain 1998;121(pt 7):1369-79 CrossRef Medline

31. Eicker SO, Turowski B, Heiroth HJ, et al. A comparative study of perfusion CT and 99m Tc-HMPAO SPECT measurement to assess cerebrovascular reserve capacity in patients with internal carotid artery occlusion. Eur J Med Res 2011;16:484-90 CrossRef Medline

32. Kawano T, Ohmori Y, Kaku Y, et al. Prolonged mean transit time detected by dynamic susceptibility contrast magnetic resonance imaging predicts cerebrovascular reserve impairment in patients with Moyamoya disease. Cerebrovasc Dis 2016;42:131-38 CrossRef Medline

33. Park JC, Kim JE, Kang HS, et al. CT perfusion with angiography as a substitute for both conventional digital subtraction angiography and acetazolamide-challenged SPECT in the follow-up of postbypass patients. Cerebrovasc Dis 2010;30:547-55 CrossRef Medline

34. Kim JH, Lee SJ, Shin T, et al. Correlative assessment of hemodynamic parameters obtained with $\mathrm{T} 2^{*}$-weighted perfusion MR imaging and SPECT in symptomatic carotid artery occlusion. AJNR Am J Neuroradiol 2000;21:1450-56 Medline

35. Yun TJ, Paeng JC, Sohn CH, et al. Monitoring cerebrovascular reactivity through the use of arterial spin labeling in patients with Moyamoya disease. Radiology 2016;278:205-13 CrossRef Medline

36. Moreton FC, Dani KA, Goutcher C, et al. Respiratory challenge MRI: practical aspects. Neuroimage Clin 2016;11:667-77 CrossRef Medline

37. Vorstrup S, Henriksen L, Paulson OB. Effect of acetazolamide on cerebral blood flow and cerebral metabolic rate for oxygen. J Clin Invest 1984;74:1634-39 CrossRef Medline

38. Murase K, Tanada S, Fujita H, et al. Kinetic behavior of technetium99m-HMPAO in the human brain and quantification of cerebral blood flow using dynamic SPECT. J Nucl Med 1992;33:135-43 Medline

39. Martin SZ, Madai VI, von Samson-Himmelstjerna FC, et al. 3D GRASE pulsed arterial spin labeling at multiple inflow times in patients with long arterial transit times: comparison with dynamic susceptibility-weighted contrast-enhanced MRI at 3 Tesla. J Cereb Blood Flow Metab 2015;35:392-401 CrossRef Medline

40. Inugami A, Kanno I, Uemura K, et al. Linearization correction of 99mTc-labeled hexamethyl-propylene amine oxime (HM-PAO) image in terms of regional CBF distribution: comparison to $\mathrm{C} 15 \mathrm{O} 2$ inhalation steady-state method measured by positron emission tomography. J Cereb Blood Flow Metab 1988;8:S52-60 CrossRef Medline

41. Fan AP, Jahanian H, Holdsworth SJ, et al. Comparison of cerebral blood flow measurement with [15O]-water positron emission tomography and arterial spin labeling magnetic resonance imaging: a systematic review. J Cereb Blood Flow Metab 2016;36:842-61 CrossRef Medline 